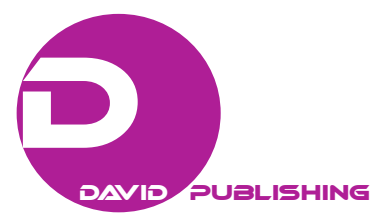

\title{
English Teachers’ Professional Sentiment and Its Cultivation
}

\author{
Jinhui Tu, Jumei Xiao \\ Huzhou Teachers College, Zhejiang, China
}

\begin{abstract}
Professional sentiment runs through the whole career of English teachers, imperceptibly changes the teaching methods, teaching attitudes, and teaching values of English teachers, and presents the characteristics of essence, dispersion, compatibility, and synchronization in its unique way. To cultivate English teachers' professional feelings, on the one hand, it is necessary for English teachers to strengthen the study of professional knowledge, develop professional ability, and maintain the feelings of English teachers forever. On the other hand, schools should create a harmonious development environment and establish a benign incentive mechanism, and at the same time, the society should also improve the status of English teachers, and increase the investment in English education resources.
\end{abstract}

Keywords: English teacher, professional sentiment, training strategies

\section{Introduction}

The professional knowledge, professional ability, and professional sentiment in teachers' professional quality are closely connected and inseparable, and they have internal consistency. Among them, the influence of professional sentiment on English teachers is profound, internal, and imperceptible, which not only plays an important role in improving English teachers' professional knowledge level and professional ability, but also plays an important role in English teachers' professional competence. The development of psychology and the way of thinking will also produce important thoughts. It is of great help to the development of English teachers' professional sentiment to study the connotation and characteristics of professional sentiment and analyze the training strategies of professional sentiment.

\section{The Connotation of English Teachers’ Professional Feelings}

Professional sentiment is "the integration of teachers' emotional attitude and values on education, the concentrated embodiment of teachers' professional ethics, and the fundamental power of teachers' professional sustainable development”. "The dynamic mechanism of teachers' professional sentiment development, the catalyst of teachers' professional happiness” (Tao, 2007), etc. English teachers' professional affection is a strong sense of identity of English teachers to their own teaching profession. They have a positive attitude to the education cause, are willing to devote their whole life to the education cause, and always maintain a good inner feeling of teachers. Generally speaking, English teachers' professional sentiment mainly includes the following three aspects:

Jinhui Tu, M.A., College of Teacher Education, Huzhou Teachers College.

Jumei Xiao, Ph.D., associate professor, College of Teacher Education, Huzhou Teachers College. 


\section{Based on Professional Ethics}

The most basic of English teachers' professional ethics is to have professional sentiment. It is the teachers' emotional experience and reflection on English education and teaching, the foundation of teachers' values and moral outlook, the important condition of forming teachers' teaching personality, and the sign of teachers' professional sentiment development. The understanding of professional sentiment will be expanded from professional ethics. First of all, English teachers should have the spirit of dedication and dedication, that is to say, they should have high professional ethics, especially in the early stage of career development, whether they agree with the profession they are engaged in, to a large extent, determines the direction of future professional development and the height they can reach. Therefore, English teachers should actively cultivate their sense of professional dedication, be loyal to and pursue the social value of English education, and be awed by the profession they are engaged in. Teachers are a profession, but only when they do not take it as a means of making a living, can they enjoy the pride brought by teaching English, enjoy the sense of achievement when students are successful in learning, enjoy their sense of responsibility as an English teacher, and truly achieve "being happy in work".

Secondly, English teachers should have the spirit of diligence and dedication, that is, the spirit of lofty professional ethics, which has added a momentum to the professional development of English teachers in the later period. English is a new language learning for students. In the deep-rooted Chinese learning mode, it is difficult to use new learning methods and learning thinking attitude. Therefore, in the face of these challenges, English teachers should be more devoted, conscientious, and enterprising. Fine industry advances on the basis of diligence. Every English teacher should be diligent in learning from experienced teachers and be good at summing up learning experience. Sharp edge of a sword comes out from grinding and plum blossom's fragrance comes from the bitter cold. The transformation from quantitative change to qualitative change will be realized one day.

\section{Take the Charm of Personality as the Link}

The personality charm of English teachers is mainly reflected in their professionalism, that is, the personality characteristics of teaching work. In order to be an excellent English teacher, we should not only have excellent professional skills, but also from our own unique personality characteristics, which will give off our own personality charm when we are engaged in teaching. For English teachers, the foundation of their own personality charm comes from their solid professional knowledge foundation and rich insight. They should not only be familiar with the cultural knowledge of China from ancient times to the present, but also have in-depth learning of Western culture. When conducting teaching research, English teachers should have keen insight, analytical ability, insight, and foresight. Through a large number of reading and analysis, it can accurately predict the current teaching difficulties and hot spots, and improve the teaching effect. At the same time, English teachers should not be constrained by the traditional teaching mode, dare to experiment and innovate, and give students different classroom atmosphere and learning mode. Of course, as a people's teacher, it is more important to have the spirit of dedication and service, love students and education. We should educate students in a different way, which combined strictness and kindness. We should not only establish the prestige of teachers, but also give them parental care. Harmonious teacher-student relationship and harmonious colleague relationship, which play an important role in the professional development of English teachers, so as to reduce the emotional burden of English teachers. 


\section{Driven by Self-Recognition}

Professional self-cognition is the psychological tendency of English teachers' self-perception and self-identification in English teaching. At the same time, the understanding of self-professional development and the perception of the future prospect of professional development are also important parts of professional self. After accepting themselves and affirming themselves, English teachers will not only have a deeper understanding of the social value of their profession, but also recognize their own self-worth. As an English teacher, we should be good at discovering the happiness brought by teaching English in the teaching process, so as to gradually form a deep sense of self-satisfaction and self-trust, and actively seek a positive professional experience. A respected and experienced English teacher has not only an independent mind and personality, an accurate understanding of his own development environment, a clear goal for his own professional development, but also a specific plan for the future prospects. All of these constitute an important part of his professional self. Professional self is also throughout the whole process of the development of professional sentiment. Whether in the early stage or in the middle and late stage of professional development, the psychological tendency and self-awareness of professional self can stimulate the development momentum of English teachers, promote their continuous learning, and improve the teaching effect.

\section{The Characteristics of English Teachers' Professional Sentiment}

To sum up, understanding the connotation of professional sentiment is helpful to further understand the permeability, compatibility, and synchronization of teachers’ professional situation.

\section{Permeability}

Penetration refers to the diffusion of liquid, gas, etc. to all sides, giving people a sense of silence, if any, if not. Just as the professional sentiment diffuses in the whole process of English teachers' professional development, it influences the English teachers' professional knowledge learning and professional ability development imperceptibly, and plays a role of moistening things and silence in the professional growth of English teachers. English teachers should make full use of the characteristics of the penetration of professional sentiment. In the process of training, professional sentiment will gradually form unique values and attitudes, and gradually penetrate into the professional development of English teachers. It can enlighten English teachers when they are in a confused period of career development, and has a clear plan for their career development.

The penetration of professional sentiment not only affects the professional knowledge and ability of English teachers, but also marks the teaching and education of English teachers. English teachers will form their own unique teaching methods and integrate the advantages of new learning teaching methods into their own teaching system. They will also have their own methods for textbook analysis and teaching research. In terms of educating students, they will also infect students with their own unique teaching attitude and emotional charm. As an internal driving force for development, professional sentiment leads English teachers to set up firm educational ideals, adhere to high professional ethics, improve unique personality characteristics, and realize their own values. In their daily teaching career, they always maintain their own feelings for teachers.

\section{Compatibility}

English teachers' professional knowledge, professional ability, and professional sentiment are integrated with each other. Solid professional knowledge is the basis for the development of professional ability, and the development of professional ability will also promote the absorption of professional knowledge. And 
professional sentiment has a profound influence on the development of professional knowledge and professional ability with a unique emotional power mechanism, so as to promote the overall development of teachers' professional quality. For the professional development of English teachers, professional knowledge and ability are the foundation, professional sentiment is the bridge, and the effective combination of them can promote the improvement of English teachers' teaching skills. Professional knowledge, professional competence, and professional sentiment as a closely linked whole can give full play to their overall functions, so that the whole teaching process of English teachers can be well connected and integrated. Of course, this teaching process includes classroom teaching, after-school reflection, and after-school research. Therefore, they do not develop independently, but need to rely on, promote, and integrate each other.

Therefore, in the process of professional development, English teachers should pay special attention to the integration of professional knowledge, professional ability, and professional sentiment into a whole, which cannot be separated from each other, not only has no effect, but also has an impact on their own professional growth.

\section{Synchronicity}

The growth of English teachers and students is synchronous. English teachers internalize what they have seen and heard into effective knowledge that can be taught to students, and promote the improvement of students' cognitive level. In the process of teaching knowledge, English teachers transfer their teaching emotions to students, and at the same time, they also use their beliefs, ideals, and values to infect students to achieve the unity of teaching and emotion. It is more effective for students to receive knowledge through emotional media, and English teachers are more likely to enjoy the sense of teaching achievement and happiness brought by students' development and progress, so as to stimulate English teachers' teaching enthusiasm and promote their own professional ability. Therefore, the development of English teachers' professional feelings and students' development are synchronous.

For English teachers themselves, the development of professional knowledge, professional ability, and professional sentiment is synchronous. However, as an English teacher, it should be noted that synchronization is not equal to equivalence. In the process of professional development, professional knowledge, professional competence, and professional affection cannot demand their development speed and development level to be the same. English teachers need to focus on the development, develop professional passion and strengthen the development of professional knowledge and professional ability. Therefore, English teachers should deal with the relationship between them and realize the synchronous development of the three.

\section{Training Strategies of English Teachers’ Professional Sentiment}

The development of English teachers' professional sentiment needs not only internal self-cultivation, but also good external development environment and scientific incentive mechanism.

\section{Cultivating English Teachers' Sentiment}

Professional sentiment is the core of English education emotion source, and professional sentiment is carried by English teachers, so "sentiment" is essential for English teachers. Emotion is a kind of noble mood and mind, infiltrating the heart bit by bit. For an English teacher, emotion is not only the expression of emotion, but also the emotional sustenance that supports him on the road of teacher. Schools can also strengthen the learning of English teachers' professional ethics and cultivate their professionalism and diligence spirit. 
Professional ethics is not only a moral bottom line, but also a legal bottom line for English teachers, which plays a role in encouraging English teachers when they are slack. If we want to get the students' wholehearted admiration, it is not enough for English teachers only to have broad knowledge, but also to infect students with their own personality charm. Students' progress is not only an affirmation of English teachers' teaching ability, but also an emotional response to English teachers. We often say that as a teacher we should have devotion to English education, which is the source of power to support teachers to devote themselves to teaching.

\section{Building a Positive Growth Environment}

Environment exerts a subtle influence on the development of English teachers. School environment is the cradle of the development of English teachers' professional feelings, and teachers' personal development also injects vitality into school development. In order to create a harmonious development environment, we can start from two aspects: professional environment and humanistic environment. First of all, to build a positive professional environment, the school should be people-oriented, strive to build a platform for the growth of English teachers, actively organize English teachers to participate in the teaching ability competition, learn the micro-classroom video of excellent English teachers, encourage English teachers to participate in more scientific research projects, participate in academic forums, constantly broaden their horizons, increase their knowledge, and improve their knowledge literacy. Secondly, we should create a warm human environment. The school should lighten the tasks of English teachers in addition to teaching, relieve their psychological pressure and mental pressure, so that English teachers have more time to invest in their professional learning and ability development, and enjoy more happiness from their own work.

\section{Improve the Evaluation System of Teachers}

The establishment of a scientific and effective incentive mechanism can not only stimulate the enthusiasm and creativity of English teachers in teaching and improve teaching efficiency, but also strengthen the professional identity of English teachers and strengthen their ideals and beliefs, which has an important impact on the cultivation of English teachers' professional feelings. The school should reasonably innovate the teacher evaluation system according to the changes of the times, adhere to the evaluation principle of "people-oriented", establish specific incentive objectives, formulate scientific incentive criteria, and assess whether an English teacher is qualified from various angles and aspects, instead of taking score as the only standard of evaluation. They are always exploring, willing to make progress, and promoting the development of professional sentiment. In terms of performance assessment, we should establish a scientific performance assessment system. We cannot use data as the only standard for assessment, so that English teachers can accept the assessment results psychologically and continue to improve. In terms of professional title evaluation and excellent evaluation, we should adhere to the principles of fairness, justice, and openness, combine the usual evaluation system, and performance evaluation results, implement democratic evaluation, explore new and effective talent models, and gradually form a new talent mechanism. Through these various forms of incentives, English teachers are aware of the glory of their profession and the loftiness of their mission and are willing to devote themselves to the cause of education.

In a word, English teachers' professional sentiment plays an extremely important role in the development of professional quality. It can enable English teachers to work with passion and live with relish, which should be the dream development realm of every English teacher. Therefore, no matter English teachers, schools, or society, they should contribute to the development of English education. 


\section{Conclusions}

To sum up, professional sentiment plays a key role in the professional development of English teachers. Through in-depth analysis of professional sentiment, professional orientation, and professional self in professional sentiment, and understand the characteristics of penetration, compatibility, and synchronization of professional sentiment, so as to help English teachers establish a scientific knowledge system of professional sentiment and lay a solid theoretical foundation for the cultivation of professional sentiment in the later stage. Because professional sentiment plays an important role in English teachers' career, we must pay attention to the cultivation of English teachers' professional sentiment. Through the cultivation of English teachers' sentiment, we can make them more firm in their professional beliefs and promote English teachers to develop their professional abilities, so as to achieve a higher level of teaching. Of course, English teachers should also strengthen the learning of professional knowledge and understand the theoretical sources behind the whole professional development.

Emotion is a main line running through the professional sentiment of English teachers. As a teacher, we should not only love our education career, but also love our students and ourselves, so that our emotional attitude towards education can be sublimated, providing a continuous driving force for the development of professional feelings. At the same time, the school and society should create a harmonious development environment and establish a benign incentive mechanism to provide solid support and guarantee for the development of English teachers' professional sentiment, so that they can devote themselves to the education career wholeheartedly, and then realize the optimization of professional feelings for the professional development of English teachers.

\section{References}

Li, Y. F. (2017). Training strategies to improve teachers’ professional sentiment. Think Tank Era, 14, 107-109.

Liu, L. (2014). Interpretation and practical construction of teachers' professional sentiment. Modern Education Science, 7, 96-98.

Sun, H. (2012). On the influence of teachers' professional feelings on teachers' professional development. China Adult Education, 23, 51-52.

Tao, X. P. (2007). Teachers' professional sentiment. Primary and Secondary School Management, 7, 54.

Wang, S. F. (2010). On teachers’ professional sentiment and its cultivation. Jiangsu Education Research, 34, 46-50.

Zhou, X. Z. (2017). IT Teachers' professional sentiment: Connotation, structure and training strategy. Journal of Zhoukou Normal University, 34(3), 130-136. 